\title{
A New Decade of Healthy People: Considerations for Comparing Youth Physical Activity Across 2 Surveillance Systems
}

\author{
Tiffany J. Chen, Kathleen B. Watson, Shannon L. Michael, Jessica J. Minnaert, \\ Janet E. Fulton, and Susan A. Carlson
}

\begin{abstract}
Background: Healthy People 2030 includes objectives to increase meeting the aerobic physical activity guideline for ages 6-13 years (of ages 6-17 y, monitored by National Survey of Children's Health [NSCH]) and grades 9 to 12 (mostly aged 14-18+ y, monitored by Youth Risk Behavior Survey [YRBS]). This study compares methodologies, prevalence, and patterns of meeting the guideline, particularly for overlapping ages 14-17 years. Methods: Nationally representative surveys, 2016-2017 NSCH (adult proxy report, 6-17 y) and 2015 and 2017 YRBS (self-report, grades 9-12), assess meeting the guideline of $\geq 60$ minutes of daily moderate to vigorous physical activity. Prevalence and odds ratios were estimated by age group and demographics. Results: For youth aged 14-17 years, 17.4\% (95\% confidence interval [CI], 16.1-18.7; NSCH) and 27.0\% (95\% CI, 25.6-28.5; YRBS) met the guideline. 25.9\% (95\% CI, 24.8-27.2) aged 6-13 years (NSCH) and 26.6\% (95\% CI, 25.3-28.0) in grades 9 to 12 (YRBS) met the guideline. Across surveys, fewer females $(P<.001)$ and Asian youth $(P<.001$ except among NSCH 14-17 y) met the guideline. Conclusions: Neither methodology nor estimates for meeting the aerobic guideline are similar across surveys, so age continuity between juxtaposed estimates should not be assumed by magnitude nor age for separate Healthy People 2030 youth physical activity objectives.
\end{abstract}

Keywords: measurement, children, adolescent, exercise, public health

Increasing physical activity is important for the health of children and adolescents, with strong evidence showing benefits, such as better cardiorespiratory and muscular fitness; smaller increases in body weight and adiposity; and improved bone mass, structure, and strength. ${ }^{1}$ Regular physical activity can be a preventive measure for chronic disease risk factors, providing youth with a higher likelihood of a healthy adulthood; it also improves brain health and cognition, impacting learning, memory, and attention, as well as decreasing symptoms of depression. ${ }^{1}$ For children and adolescents ages 6-17 years, the Physical Activity Guidelines for Americans, second edition recommends the aerobic guideline of 60 minutes $(1 \mathrm{~h})$ or more of moderate to vigorous physical activity daily. ${ }^{2}$

Healthy People is the leading disease prevention and health promotion road map in the United States, providing 10-year objectives in a variety of topic areas for promoting healthy behaviors, such as increasing physical activity, ${ }^{3}$ including for

\footnotetext{
Chen, Watson, Fulton, and Carlson are with the Division of Nutrition, Physical Activity, and Obesity, National Center for Chronic Disease Prevention and Health Promotion, Centers for Disease Control and Prevention, U.S. Department of Health and Human Services, Atlanta, GA, USA. Chen is also with the Oak Ridge Institute for Science and Education (ORISE) Research Participation Program supporting the Division of Nutrition, Physical Activity, and Obesity, National Center for Chronic Disease Prevention and Health Promotion, Centers for Disease Control and Prevention, Atlanta, GA, USA. Michael is with the Division of Diabetes Translation, National Center for Chronic Disease Prevention and Health Promotion, Centers for Disease Control and Prevention, U.S. Department of Health and Human Services, Atlanta, GA, USA. Minnaert is with the Maternal and Child Health Bureau, Health Resources and Services Administration, U.S. Department of Health and Human Services, Rockville, MD, USA. Carlson is also with the Division of Population Health, National Center for Chronic Disease Prevention and Health Promotion, Centers for Disease Control and Prevention, U.S. Department of Health and Human Services, Atlanta, GA, USA. Chen (pgi8@cdc.gov) is corresponding author.
}

youth (defined in this study as a broad term including any age through the end of high school). For the past decade, Healthy People 2020 included a youth physical activity objective to increase the proportion of adolescents (defined in this study, according to this objective, as youth in grades 9-12 surveyed by the national Youth Risk Behavior Survey [YRBS]) who met the physical activity guideline for aerobic physical activity, which continues in Healthy People 2030 with objective PA-06. ${ }^{4}$ Healthy People 2030 also expands monitoring of youth meeting the aerobic guideline with a new objective (PA-09) among children (defined in this study, according to PA-09, as youth ages 6-13 y surveyed by the National Survey of Children's Health $[\mathrm{NSCH}])^{5}$

Two surveillance systems are being used to monitor prevalence estimates for the new decade's youth aerobic physical activity objectives. As part of the Youth Risk Behavior Surveillance System, the YRBS 6 will monitor adolescents in grades 9 to 12 , mostly aged 14-18+ years (as was done for Healthy People 2020) for PA- $06,{ }^{4}$ allowing the continued assessment of both longer aerobic trends over time, as well as the full youth physical activity guidelines that include muscle-strengthening activity. Since $<1 \%$ of YRBS data are comprised of high school students aged 13 years or younger, ${ }^{7,8}$ there was a gap in monitoring youth younger than high school age, 13 years or younger. Consequently, the $\mathrm{NSCH}^{9}$ will be a new surveillance addition for monitoring children ages $6-13$ years for PA- 09.5

The baseline for PA-06 is $26.1 \%$ (YRBS, 2017) and the baseline for PA-09 is $25.9 \%$ (NSCH, 2016-2017). ${ }^{4,5}$ Because both objectives are set using the same physical activity guideline, people may assume similarity and age continuity between the children's (aged 6-13 y) and adolescents' (mostly aged 14-18+ y) baseline magnitudes, though the 2 estimates are from different systems. However, previous comparisons of surveillance systems with differing methodologies have resulted in different prevalence estimates, ${ }^{10-12}$ with implications for monitoring trends and objectives 
over time. Moreover, levels of physical activity in youth have been found to decrease as age increases, ${ }^{13-15}$ so investigating prevalence by various age groups, including those beyond the objectives and overlapping across systems, can help clarify overarching age patterns. Other demographic patterns between systems and age groups can also point to where targeted interventions may be needed to meet each objective.

Therefore, an analysis of how these 2 system surveys compare is timely for the interpretation of Healthy People 2030 data, particularly in examining data collection methodology and estimates and patterns by overlapping ages. Adding to this information's importance, the Health Resources and Services Administration's Maternal and Child Health Bureau monitors the Title V Maternal and Child Health Services Block Grant National Performance Measure number $8,{ }^{16}$ which displays juxtaposed physical activity estimates from $\mathrm{NSCH}$ and YRBS data to drive improvement related to youth obesity. A closer examination of these systems can also assist state efforts in measuring progress for this performance measure. First, this study will provide a summary of physical activity data collection methods in the 2 system surveys, NSCH and YRBS. Second, this study will use these data for 3 purposes: (1) to compare unadjusted prevalence estimates across NSCH and YRBS of youth who met the aerobic physical activity guideline in overlapping ages, specifically 14-17 years, (2) to compare demographic patterns across NSCH and YRBS in the overlapping ages 14-17 years, and (3) to compare demographic patterns across NSCH and YRBS in the age groups used for Healthy People 2030 objectives PA-06 and PA-09. Understanding how these systems, estimates, and patterns are similar or different will enable users of these data to better interpret comparisons, utilizing the data in appropriate ways for measuring progress, guiding decisions, and prioritizing those in need to increase youth physical activity and achieve Healthy People 2030 objectives.

\section{Methods}

\section{Survey Descriptions}

The NSCH and YRBS, the 2 surveillance system surveys being used to monitor the Healthy People 2030 youth aerobic physical activity objectives, were compared. Data were combined from the 2 most recent and comparable survey periods for each system, 2016$2017 \mathrm{NSCH}$ and 2015 and 2017 YRBS, to increase the sample size for subgroup estimates. The systems' survey design, operation, and other characteristics are described in detail elsewhere ${ }^{6,9,17-19}$ and are summarized here.

The NSCH. The NSCH, funded and directed by the Health Resources and Services Administration's Maternal and Child Health Bureau, is a self-administered mail- and web-based survey of a random address-based sample of US households in the 50 states and the District of Columbia selected from the Census Master Address File. A screener survey was used to identify households with children $(0-17 \mathrm{y})$. One child per household was randomly selected, and a parent or guardian respondent in the household who knew about the health and health care of the selected child was given an age-specific topical survey regarding the child. Since 2016, NSCH has been conducted annually, collecting physical activity data every year. In 2017, the survey's weighted interview completion rate was $70.9 \%$ and weighted overall response rate was $37.4 \%$; in 2016 , they were $69.7 \%$ and $40.7 \%$, respectively. ${ }^{9,17,18}$ Using 2016-2017 NSCH data as consistent with the Healthy People 2030 baseline, our analytic sample included 50,191 adult respondents answering as proxies for youth ages 6-17 years; data from 965 respondents were excluded due to missing responses to the physical activity question.

The YRBS. The national YRBS, conducted as part of the Youth Risk Behavior Surveillance System by the Division of Adolescent and School Health at the Centers for Disease Control and Prevention, is a self-administered school-based survey of a nationally representative sample of US public and private school students in grades 9 to 12 in the 50 states and the District of Columbia. It used a 3 -stage cluster sample design, with the first-stage sampling frame of counties as primary sampling units. The second-stage sampling frame of schools with grades 9 to 12 was sampled from those primary sampling units. The third stage randomly sampled one or 2 classrooms of a required subject or period in each grade. All students in these classrooms were eligible to be respondents. YRBS is conducted biennially, collecting physical activity data each administration. In both 2015 and 2017, the survey's overall response rate was $60 \%$; in 2015 , the school response rate was $69 \%$ and the student response rate was $86 \%$, while in 2017 , they were $75 \%$ and $81 \%$, respectively. ${ }^{6,19}$ Although the Healthy People 2030 baseline uses only 2017 data, our analytic sample used 2015 and 2017 data to be consistent in comparing with NSCH and included 29,483 respondents; data from 906 respondents were excluded due to missing responses to the physical activity question.

\section{Measures}

Specific information about how each surveillance system assessed youth aerobic physical activity is in Table 1. Respondents were classified as meeting the aerobic component of the guideline with daily (every day or $7 \mathrm{~d}$ ) moderate to vigorous physical activity for at least 60 minutes per day during the past week, according to the Physical Activity Guidelines for Americans, second edition. ${ }^{2}$ The demographic characteristics reported for both NSCH and YRBS included sex (male and female); age groups (NSCH: 6-13, 14-17 y; YRBS: overall grades 9-12, 14-17 y); and race/ethnicity (non-Hispanic Asian only, non-Hispanic Black or African American only, non-Hispanic White only, non-Hispanic Other or 2 or more races, Hispanic or Latino). The demographic characteristics reported only for NSCH included household income level categorized by federal poverty level (FPL) (0\%-99\% FPL, 100\%$199 \%$ FPL, 200\%-399\% FPL, 400\% FPL or above); highest education of adult in household (less than high school, high school degree or general educational development [equivalent to high school completion], some college or technical school, college degree or higher); and region (Northeast, Midwest, South, and West).

\section{Statistical Analysis}

Data from the 2 surveillance system surveys were analyzed separately to estimate the prevalence and $95 \%$ confidence intervals (95\% CIs) of youth meeting the aerobic physical activity guideline. Analysis of these data was exempt from the Centers for Disease Control and Prevention's Institutional Review Board approval because they are public use data. For 2016-2017 NSCH, data were analyzed in 2 age groups: 6-13 years (consistent with Healthy People children's objective PA-09) and 14-17 years (overlaps with the YRBS sample). For 2015 and 2017 YRBS, data were analyzed overall (consistent with Healthy People adolescents' objective PA-06) and 14-17 years (overlaps with the NSCH sample). Significant differences by sex and race/ethnicity (NSCH and YRBS) and age group, household income level, highest education of adult in 
Table 1 Characteristics of Youth Surveillance System Surveys for Aerobic Physical Activity

\begin{tabular}{|c|c|c|}
\hline Category & NSCH & YRBS \\
\hline $\begin{array}{l}\text { Survey years included in } \\
\text { the analysis }\end{array}$ & 2016, 2017 & 2015,2017 \\
\hline $\begin{array}{l}\text { Sampling design and } \\
\text { frame }\end{array}$ & $\begin{array}{l}\text { Random address-based sample of households in the } 50 \\
\text { states and the District of Columbia; only one child } \\
\text { sampled per given household }\end{array}$ & $\begin{array}{l}\text { 3-stage, cluster sample design producing a nationally repre- } \\
\text { sentative sample of US public and private school students in } \\
\text { grades } 9-12 \text { in the } 50 \text { states and the District of Columbia }\end{array}$ \\
\hline $\begin{array}{l}\text { Overall response rate }{ }^{a} \text { for } \\
\text { years of data analyzed }\end{array}$ & $\begin{array}{l}37.4 \%(2017) \\
40.7 \%(2016)\end{array}$ & $\begin{array}{l}60 \%(2017) \\
60 \%(2015)\end{array}$ \\
\hline Respondent & $\begin{array}{l}\text { Adult proxy report (parent or guardian who lived in the } \\
\text { household) }\end{array}$ & Self-reported \\
\hline Collection method (mode) & Self-administered mail- and web-based survey & Self-administered school-based survey \\
\hline Age or grade range & Aged 6-17 y & Grades $9-12$ \\
\hline $\begin{array}{l}\text { Aerobic physical activity } \\
\text { question }\end{array}$ & $\begin{array}{l}\text { During the past week, on how many days did this child } \\
\text { exercise, play a sport, or participate in physical activity } \\
\text { for at least } 60 \mathrm{~min} \text { ? }\end{array}$ & $\begin{array}{l}\text { During the past } 7 \mathrm{~d} \text {, on how many days were you physically } \\
\text { active for a total of at least } 60 \text { min per day? (Add up all the } \\
\text { time you spent in any kind of physical activity that increased } \\
\text { your heart rate and made you breathe hard some of the time.) }\end{array}$ \\
\hline Recall period(s) & Past week & Past $7 \mathrm{~d}$ \\
\hline Response options & $0 \mathrm{~d}, 1-3 \mathrm{~d}, 4-6 \mathrm{~d}$, every day & $0 \mathrm{~d}, 1 \mathrm{~d}, 2 \mathrm{~d}, 3 \mathrm{~d}, 4 \mathrm{~d}, 5 \mathrm{~d}, 6 \mathrm{~d}, 7 \mathrm{~d}$ \\
\hline $\begin{array}{l}\text { Survey years with } \\
\text { consistent aerobic } \\
\text { physical activity question }\end{array}$ & $2016,2017,2018$ & $2005,{ }^{\text {b }} 2007,2009,2011,2013,2015,2017$ \\
\hline $\begin{array}{l}\text { Other forms of youth } \\
\text { physical activity assessed }\end{array}$ & Sports team or lessons participation & $\begin{array}{l}\text { Muscle-strengthening exercises, physical education class } \\
\text { attendance, sports team participation }\end{array}$ \\
\hline \multicolumn{3}{|c|}{ 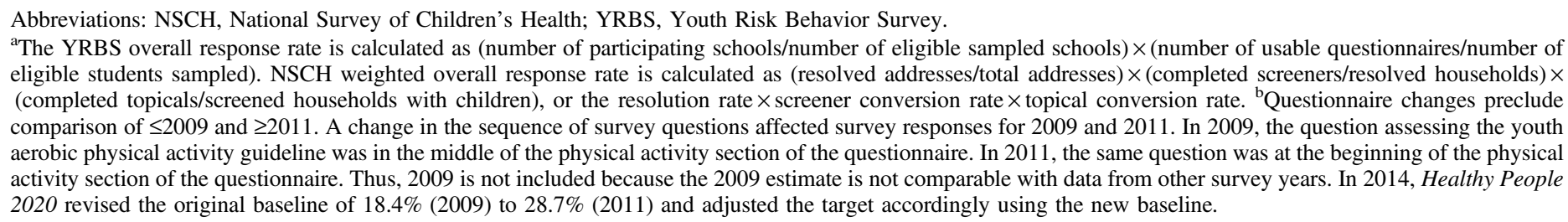 } \\
\hline
\end{tabular}

household, and region (NSCH only) were assessed with pairwise $t$ tests. Simple logistic regression analyses were conducted for both $\mathrm{NSCH}$ and YRBS to assess the unadjusted association between youth characteristics and meeting the aerobic physical activity guideline in ages $14-17$ years. Significance level was $P<.05$. Bonferroni adjustments were used for multiple comparisons. Because of the heterogeneity of the race/ethnicity group of NonHispanic Other or 2 or more races, results for this group are not interpreted. SAS-callable SUDAAN (version 11.0; Research Triangle Institute, Research Triangle Park, NC) was used for all analyses to account for survey design and weights.

\section{Results}

\section{Comparison}

In the overlapping ages $14-17$ years, $17.4 \%$ of youth surveyed by $\mathrm{NSCH}$ met the aerobic physical activity guideline, as compared with the $27.0 \%$ surveyed by YRBS. Across both NSCH and YRBS in ages 14-17 years, males had more than 2 times higher odds of meeting the guideline than did females (Table 2). In YRBS but not NSCH, Asian youth ages 14-17 years had half the odds of meeting the guideline than did White youth of the same age group.

\section{National Survey of Children's Health}

Overall, $23.1 \%$ of youth aged 6-17 years met the aerobic physical activity guideline. Significantly more children aged 6-13 years
(25.9\%) met the guideline than did youth aged 14-17 years $(17.4 \%)(P<.001)$ (Table 3).

Among youth aged 14-17 years, more males than females met the guideline $(P<.001)$, and the proportion who met the guideline decreased linearly with increasing household income level $(P<.001)$.

Among children aged 6-13 years, significant differences were observed across all characteristics (Table 3). A higher proportion of males than females $(P<.001)$, non-Hispanic Black or African American (Black) and non-Hispanic White (White) children than non-Hispanic Asian (Asian) children $(P<.001)$, children living in households where the highest education of at least one adult was some college or technical school than those in households where the highest education was a college degree and higher $(P<.001)$, and children living in the Midwest than those living in the South regions $(P<.01)$ met the guideline. The prevalence of meeting the guideline decreased linearly with increasing household income level $(P<0.001)$.

\section{Youth Risk Behavior Survey}

Among youth aged 14-17 years, 27.0\% met the guideline. The prevalence of meeting the guideline was higher for males than females $(P<.001)$ and Black, White, and Hispanic or Latino youth than Asian youth $(P<.001)$ (Table 4$)$.

Overall, for adolescents in grades 9 to $12,26.6 \%$ met the aerobic guideline. The same patterns, as with adolescents aged 14-17 years, were seen by sex and race/ethnicity. 
Table 2 The ORs With 95\% Cl of Youth Ages 14-17 Years Meeting Aerobic Physical Activity Guideline by Sex and Race/Ethnicity, NSCH 2016-2017 and YRBS 2015-2017

\begin{tabular}{lcc}
\hline Characteristics & NSCH 2016-2017 & YRBS 2015-2017 $^{\mathbf{b}}$ \\
\hline Sex & $2.15(1.79-2.59)$ & $2.63(2.41-2.87)$ \\
$\quad$ Male & Referent & Referent \\
$\quad$ Female & & $0.52(0.40-0.68)^{*}$ \\
Race/ethnicity & $0.96(0.57-1.60)$ & $0.84(0.70-1.00)$ \\
Non-Hispanic Asian only & $1.32(1.00-1.75)$ & Referent \\
Non-Hispanic Black or African American only & Referent & $1.11(0.94-1.30)$ \\
Non-Hispanic White only & $1.08(0.81-1.43)$ & $0.86(0.75-0.99)$ \\
Non-Hispanic Other or 2 or more races & $1.05(0.79-1.39)$ & \\
Hispanic or Latino &
\end{tabular}

Abbreviations: CI, confidence interval; NSCH, National Survey of Children's Health; OR, odds ratio; YRBS, Youth Risk Behavior Survey.

${ }^{a}$ Respondents for whom aerobic physical activity data were missing $(n=440)$ have been excluded for our analysis. ${ }^{b}$ Respondents for whom aerobic physical activity data were missing $(\mathrm{n}=787)$ have been excluded for our analysis. For estimates stratified by sex, those with unknown sex $(\mathrm{n}=99)$ were excluded; for estimates stratified by race/ ethnicity, those with unknown race/ethnicity $(n=456)$ were excluded.

*Based on the Bonferroni correction, this racial/ethnic group was the only group significantly different from the referent group.

Table 3 Prevalence of Youth Meeting Aerobic Physical Activity Guideline by Age Group, NSCH 2016-2017

\begin{tabular}{|c|c|c|c|c|}
\hline \multirow[b]{2}{*}{ Characteristics } & \multicolumn{2}{|c|}{$6-13 y$} & \multicolumn{2}{|c|}{$14-17 y$} \\
\hline & $\begin{array}{l}\text { Sample size } \\
\text { unweighted }\end{array}$ & $\begin{array}{c}\% \text { Meet Aerobic } \\
\text { Guideline }(95 \% \mathrm{Cl})\end{array}$ & $\begin{array}{l}\text { Sample size } \\
\text { unweighted }\end{array}$ & $\begin{array}{c}\% \text { Meet Aerobic } \\
\text { Guideline }(95 \% \mathrm{Cl})\end{array}$ \\
\hline Total $^{\mathrm{b}}$ & 29,531 & $25.9(24.8-27.2)$ & 20,660 & $17.4(16.1-18.7)$ \\
\hline \multicolumn{5}{|l|}{$\operatorname{Sex}^{\mathrm{c}}$} \\
\hline Male & 15,149 & v28.5 (26.9-30.2) & 10,513 & ${ }^{\mathrm{v}} 22.6(20.5-24.8)$ \\
\hline Female & 14,382 & w/23.2 (21.5-25.0) & 10,147 & w $11.9(10.6-13.4)$ \\
\hline \multicolumn{5}{|l|}{ Race/ethnicity } \\
\hline Non-Hispanic Asian only & 1561 & v16.5 (13.1-20.7) & 1089 & $16.0(10.3-23.9)$ \\
\hline $\begin{array}{l}\text { Non-Hispanic Black or African } \\
\text { American only }\end{array}$ & 1810 & ${ }^{\mathrm{w}} 27.5(24.1-31.2)$ & 1264 & $20.7(16.7-25.5)$ \\
\hline Non-Hispanic White only & 20,352 & w2 $27.7(26.5-29.0)$ & 14,868 & $16.5(15.4-17.8)$ \\
\hline $\begin{array}{l}\text { Non-Hispanic Other or } 2 \text { or more } \\
\text { races }\end{array}$ & 2305 & ${ }^{\mathrm{w}} 26.9(23.2-30.9)$ & 1366 & $17.6(14.0-21.9)$ \\
\hline Hispanic or Latino & 3503 & $22.9(19.8-26.4)$ & 2073 & $17.2(13.7-21.4)$ \\
\hline \multicolumn{5}{|l|}{ Household income level $^{\mathrm{d}}$} \\
\hline $0 \%-99 \%$ FPL & 3245 & v31.9 (28.5-35.5) & 2041 & v20.7 (17.4-24.4) \\
\hline $100 \%-199 \%$ FPL & 4823 & $26.2(23.5-29.0)$ & 2991 & 'v20.3 (17.0-24.0) \\
\hline $200 \%-399 \%$ FPL & 8985 & ${ }^{\mathrm{w}} 24.0(22.1-26.0)$ & 6164 & $16.5(14.0-19.2)$ \\
\hline $400 \%$ FPL or above & 12,478 & w23.1 (21.7-24.6) & 9464 & ${ }^{\mathrm{w}} 14.1(12.6-15.7)$ \\
\hline \multicolumn{5}{|l|}{$\begin{array}{l}\text { Highest education of adult in } \\
\text { household }\end{array}$} \\
\hline Less than high school & 662 & $29.0(23.3-35.5)$ & 492 & $17.6(12.1-24.9)$ \\
\hline High school degree or GED & 3690 & $26.6(23.7-29.7)$ & 2848 & $20.1(16.8-24.0)$ \\
\hline Some college or technical school & 6683 & v29.0 (26.6-31.6) & 4922 & $18.8(16.2-21.7)$ \\
\hline College degree or higher & 18,055 & w23.5 (22.2-24.9) & 12,089 & $15.3(14.0-16.6)$ \\
\hline \multicolumn{5}{|l|}{ Region } \\
\hline Northeast & 5546 & $24.6(22.2-27.2)$ & 4005 & $16.5(14.1-19.2)$ \\
\hline Midwest & 7465 & v28.4 (26.5-30.3) & 5280 & $17.7(15.7-19.8)$ \\
\hline South & 8927 & ${ }^{w} 24.4(22.7-26.3)$ & 6229 & $18.0(15.8-20.5)$ \\
\hline West & 7593 & $27.1(24.0-30.4)$ & 5146 & $16.5(13.6-19.9)$ \\
\hline
\end{tabular}

Abbreviations: CI, confidence interval; FPL, federal poverty level; GED, General Educational Development; NSCH, National Survey of Children's Health.

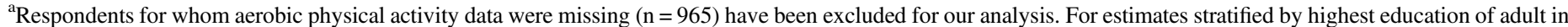

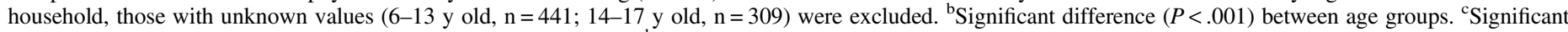

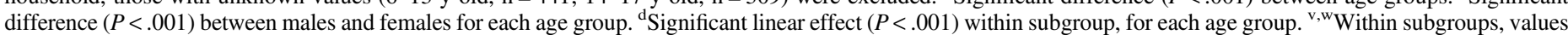
are significantly different from each other (Bonferroni corrected $P<.05$ ). 
Table 4 Prevalence of Youth Meeting Aerobic Physical Activity Guideline by Age Group, YRBS 2015-2017

\begin{tabular}{|c|c|c|c|c|}
\hline \multirow[b]{2}{*}{ Characteristics } & \multicolumn{2}{|c|}{ Overall $^{b}$} & \multicolumn{2}{|c|}{$14-17 y$} \\
\hline & $\begin{array}{l}\text { Sample size } \\
\text { unweighted }\end{array}$ & $\begin{array}{c}\% \text { Meet Aerobic } \\
\text { Guideline }(95 \% \mathrm{Cl})\end{array}$ & $\begin{array}{l}\text { Sample size } \\
\text { unweighted }\end{array}$ & $\begin{array}{c}\% \text { Meet Aerobic } \\
\text { Guideline }(95 \% \mathrm{Cl})\end{array}$ \\
\hline Total & 29,483 & $26.6(25.3-28.0)$ & 25,387 & $27.0(25.6-28.5)$ \\
\hline \multicolumn{5}{|l|}{$\operatorname{Sex}^{\mathrm{c}}$} \\
\hline Male & 14,325 & v35.7 (34.1-37.3) & 12,229 & v36.5 (34.7-38.2) \\
\hline Female & 14,927 & ${ }^{\mathrm{w}} 17.6(16.4-18.9)$ & 13,059 & ${ }^{\mathrm{w}} 17.9(16.6-19.3)$ \\
\hline \multicolumn{5}{|l|}{ Race/ethnicity } \\
\hline Non-Hispanic Asian only & 1251 & v $17.1(14.1-20.7)$ & 1073 & v17.1 (14.0-20.8) \\
\hline $\begin{array}{l}\text { Non-Hispanic Black or African } \\
\text { American only }\end{array}$ & 4173 & ${ }^{\mathrm{w}} 24.3(22.0-26.8)$ & 3556 & ${ }^{\mathrm{w}} 25.0(22.2-28.0)$ \\
\hline Non-Hispanic White only & 12,904 & ${ }^{\mathrm{w}} 28.1(26.3-30.1)$ & 11,329 & ${ }^{\mathrm{w}} 28.5(26.5-30.6)$ \\
\hline $\begin{array}{l}\text { Non-Hispanic Other or } 2 \text { or more } \\
\text { races }\end{array}$ & 2017 & w29.9 (26.9-33.1) & 1347 & w30.4 (27.3-33.8) \\
\hline Hispanic or Latino & 8490 & w25.2 (23.5-27.0) & 7192 & ${ }^{w} 25.5(23.7-27.5)$ \\
\hline
\end{tabular}

Abbreviations: CI, confidence interval; YRBS, Youth Risk Behavior Survey.

${ }^{\text {a }}$ Respondents for whom aerobic physical activity data were missing $(n=906)$ have been excluded for our analysis. For estimates stratified by sex, those with unknown sex $(\mathrm{n}=231)$ were excluded; for estimates stratified by race/ethnicity, those with unknown race/ethnicity $(\mathrm{n}=648)$ were excluded. ${ }^{\mathrm{b}}$ Overall respondents are students in grades 9 to 12 , including those of unknown age $(n=136), 13$ years or younger $(n=129)$, and 18 years or older $(n=3831)$; however, estimates for these age groups are not reported. ${ }^{\mathrm{c}}$ Significant difference $(P<.001)$ between males and females overall and for the age group $14-17$ years. ${ }^{\mathrm{v}, \mathrm{w}}$ Within subgroups, values are significantly different from each other (Bonferroni corrected $P<.05$ ).

\section{Discussion}

Similar to Healthy People 2030's baseline estimates for monitoring the new decade's objectives, ${ }^{4,5}$ this study found that $25.9 \%$ of children aged $6-13$ years surveyed by NSCH and $26.6 \%$ of adolescents surveyed by YRBS (grades 9-12) met the youth aerobic physical activity guideline. However, when estimates across the 2 surveillance systems were compared in the overlapping age group of 14-17 years, prevalence of youth meeting the guideline differed by 9.6 percentage points between the combined 2016-2017 NSCH data (17.4\%) and the combined 2015 and 2017 YRBS data (27.0\%). Users of these data and Healthy People 2030 might be tempted to assume similarity between estimates from the 2 systems or age continuity in estimates between Healthy People 2030's child and adolescent physical activity objectives. However, this study's comparisons demonstrate that similarity and age continuity, based on estimates' magnitudes between objectives, should not be assumed.

\section{Differences Between NSCH and YRBS}

Several methodological differences may inform comparisons across the 2 system surveys. Perhaps the most notable difference between them is that each relies on different respondents; YRBS uses selfreporting adolescents as respondents while NSCH uses adult proxies (ie, a parent or guardian who lives in the household and who knows about the health and health care of the child). ${ }^{17,18}$ It is possible that some of the 9.6 percentage point difference between NSCH and YRBS youth aged 14-17 years is due to differences in the accuracy of reporting by adult proxies and adolescents. However, this study is not able to examine this specifically. One study showed that adolescents can report hours of very hard physical activity with moderate validity as correlated with minutes spent in same-day activity intervals with heart rate $\geq 140$ and $\geq 160,{ }^{20}$ and a systematic review found that the correlations of adolescents' physical activity questionnaires with their accelerometer scores were stronger than those for children. ${ }^{21}$ As correlations of physical activity reports in children were weaker ${ }^{21}$; asking adult proxies may help address potential issues with reports from younger children, such as their cognitive limitations. ${ }^{22}$ Despite this, examples from research on topics other than physical activity have shown that adult proxies report differently than the youth they report on, which can result in both underreporting and overreporting depending on the outcome, ${ }^{23-}$ 25 particularly for youth behaviors occurring outside the home that adults may not be aware of. ${ }^{26}$ The influence that different respondents, particularly various adult proxies, have on reporting youth physical activity may be an area of future research to help explain the differences in physical activity estimates between NSCH and YRBS.

Specific physical activity assessment characteristics, such as different questions assessing activity, may be another difference informing comparisons across the 2 system surveys. For example, the question posed by NSCH included examples of activities (ie, exercise and playing a sport), while the question posed by YRBS defined moderate- to vigorous-intensity activity (ie, increased heart rate and breathing hard some of the time). Previous research demonstrates that variations in surveillance questions may produce different estimates, such as with domains (ie, leisure, household, transport), intensities, and amounts of activities mentioned. ${ }^{10}$ Though neither system specifies domains, NSCH's inclusion of more examples and lack of defined intensity may have resulted in the higher prevalence estimates observed, with the possibility of respondents counting lighter intensity activities as exercising and playing sports. In contrast, YRBS's specific definition of moderateto vigorous-intensity activity and lack of examples may have resulted in the lower estimates observed.

Finally, the system surveys also differed in general characteristics, such as sampling design and response rate, adding to the inappropriateness of comparison without context. For example, NSCH's address-based sampling design excluded institutionalized youth and youth not associated with an address. ${ }^{17,18}$ YRBS's school-based sampling design excluded out-of-school youth. ${ }^{6,19}$ Compared with YRBS's response rates around $60 \%,{ }^{6,19} \mathrm{NSCH}$ had lower rates around $40 \%$, though nonresponse bias analyses concluded no strong evidence of nonresponse bias in 2016 and 2017 NSCH data. ${ }^{27,28}$ Physical activity behaviors related to excluded or 
nonresponsive students in either or both NSCH and YRBS samples could differentially influence the estimates of physical activity to be lower or higher.

\section{Patterns of Youth Meeting the Aerobic Physical Activity Guideline}

Research comparing physical activity surveillance systems with methodological differences have noted that while prevalence estimates may differ, ${ }^{10-12}$ similar patterns by characteristics emerge. ${ }^{10,12}$ In this study, all prevalence estimates, including those compared in youth 14-17 years, were significantly lower in females than in males. Patterns by sex and age found in comparing surveys and age groups in this study were similar to those in other studies. ${ }^{13-15,29}$

For the most part, aerobic physical activity patterns were similar by race/ethnicity in NSCH and YRBS, with one particular exception in NSCH youth 14-17 years. In the overlapping age group of 14-17 years, the exception was that there were no significant differences by race/ethnicity for youth surveyed by $\mathrm{NSCH}$ though prevalence was lowest in Asian youth, whereas significantly fewer Asian youth than youth of all other races/ ethnicities (YRBS) engaged in the recommended amount of aerobic physical activity. Prevalence was also significantly lower in Asian youth than Black and White youth for children 6-13 years (NSCH) and youth of all other races/ethnicities for overall adolescents in grades 9 to 12 (YRBS), the 2 Healthy People 2030 objective groups.

The significant findings by race/ethnicity are supported by other studies. For example, Asian males and females in a nationally representative sample of grades 7 to 12 were least likely to engage in high levels of moderate to vigorous activity when compared with their White, Black, and Hispanic counterparts ${ }^{15}$; in a longitudinal study of adolescent students, both Asian males and females in middle school had significantly lower levels of moderate to vigorous activity than their White counterparts. ${ }^{30}$ For both surveys in all age groups, there were no significant differences among other races/ethnicities. Previous evidence on differences by other racial/ ethnic groups is inconsistent, particularly by age. Some studies found that white children are less active than black children ${ }^{31,32}$ and another found the opposite in adolescents. ${ }^{33}$ As fewer Asian children and adolescents met the aerobic physical activity guideline than other youth in both Healthy People 2030 objective groups, strategies to increase activity among Asian youth may help reduce racial/ethnic disparities in youth physical activity to achieve Healthy People's goal of health equity.

As assessed by NSCH's wider age range of 6-17 years, prevalence of meeting the aerobic guideline in youth 14-17 years was significantly lower than in children 6-13 years in the single survey. Middle and high school students are less likely to be physically active for 60 minutes every day than elementary school children. ${ }^{31,34}$ In addition, 3 nationally representative studies of US youth throughout younger and older age ranges found lower levels of activity in older ages, as well as in females when compared with males. ${ }^{13-15}$ Strategies that help to engage females and address the issue of decreasing activity from childhood into adolescence may be important to achieving Healthy People 2030 objectives. Notably, the observed decline in meeting the guideline between children and older youth in NSCH provides further evidence that the lack of a change in physical activity between the child and adolescent objectives measured with 2 different surveillance systems should not be interpreted as reflecting actual patterns in age.
Investigating other demographic characteristics beyond sex and race/ethnicity across NSCH's wider age range displays how differences may appear between younger and older youth, even in a single system survey. Differences by socioeconomic status (SES) were only assessed by NSCH; youth in both age ranges of 6-13 and 14-17 years presented a significant linear decrease in prevalence of meeting the aerobic guideline with increasing household income level, while a significant difference by highest household education was only seen in children 6-13 years, with higher prevalence among children in a household with some college or technical school compared with those in a household with a college degree and higher. In contrast to our findings, some studies observed a relationship between higher household SES (ie, income and adult educational attainment) and increased physical activity, ${ }^{35,36}$ possibly from restricted opportunities or barriers to activity with lower SES. ${ }^{36-38}$ However, other studies found no relationship between SES and child or adolescent activity ${ }^{33,39}$ or an inverse relationship $^{40}$ similar to those in this study. Conflicting findings may be due to different measures of SES $^{33}$ and physical activity. ${ }^{39,40}$ In one example, family SES, a proxy combining income with household education, showed a significant positive relationship with children's sports participation but not overall, moderate, and vigorous physical activity, while parental education alone positively predicted children's sports participation and physical activity. ${ }^{41}$ Further research may be warranted to elucidate the influences of various SES measures on multiple aspects of youth physical activity at different ages.

Differences by region were only seen in children 6-13 years in $\mathrm{NSCH}$, with higher prevalence of meeting the aerobic guideline for those living in the Midwest than in the South. A study that examined physical activity environment reinforced these regional patterns, as the South had environments with low physical activity scores and the Midwest had high scores. ${ }^{42}$ A longitudinal study found that youth in the Midwest had higher physical activity levels, though not significant, than youth in other regions; as they aged from 9 to 15 years, Midwestern youth's activity levels declined at significantly faster rates for both genders, ${ }^{43}$ which may explain why the current study found no significant difference by region in youth aged 14-17 years. Information on regional youth physical activity from NSCH can be used to help inform efforts to increase activity, particularly for children living in the South; in addition, available state-level data ${ }^{44}$ for $\mathrm{NSCH}^{45}$ and $\mathrm{YRBS}^{46}$ can also help inform specific state efforts toward achieving Healthy People objectives.

\section{Limitations}

This study has several limitations. In addition to each system's limitations of recall and social desirability biases from respondent reporting ${ }^{21,47-49}$ and nonresponse bias related to response rates, another limitation of this study is that it could not be used to assess which of the measures was more accurate. Furthermore, the different survey questions compared between NSCH and YRBS use language that may not be specific enough to measure only aerobic physical activity, resulting in the possibility of undetermined over- or underestimates of aerobic physical activity; differences in comparing surveillance systems and surveys may extend beyond differences in device-based instruments and methods, further limiting broad comparison of physical activity estimates. Also, seasonal variations in response to the physical activity question could not be accounted for. Other factors that may influence physical activity were not assessed, such as disability 
or long-standing conditions. Finally, assessing physical activity daily, per the guideline followed in this study, rather than on average, could substantially affect prevalence estimates to appear lower than if assessing by average activity. ${ }^{50}$

\section{Conclusions}

A total of $25.9 \%$ of children aged 6-13 years surveyed by 2016 $2017 \mathrm{NSCH}$ and $26.6 \%$ of adolescents in grades 9 to 12 surveyed by 2015 and 2017 YRBS met the aerobic physical activity guideline. However, the 9.6 percentage point difference between NSCH and YRBS estimates for youth aged 14-17 years suggests that the estimates of similar magnitude between the child and adolescent Healthy People 2030 objective groups may be a result of using 2 different surveillance systems. Those using Healthy People 2030 youth physical activity objectives data should not assume the same activity levels nor age continuity between child and adolescent objectives. Regardless, patterns by sex and race/ethnicity were generally similar across system surveys. As a new decade of monitoring youth physical activity objectives begins, it is important to understand similarities and differences between systems for contextualizing estimates and guiding decisions to increase physical activity.

\section{Acknowledgments}

The findings and conclusions in this manuscript are those of the authors and do not necessarily represent the official position of the US Department of Health and Human Services, Centers for Disease Control and Prevention, or the Health Resources and Services Administration. The authors declared no potential conflicts of interest with respect to the research, authorship, and/or publication of this article. The authors received no financial support for the research, authorship, and/or publication of this article.

\section{References}

1. Physical Activity Guidelines Advisory Committee. 2018 Physical Activity Guidelines Advisory Committee Scientific Report. Washington, D.C.: U.S. Department of Health and Human Services; 2018.

2. U.S. Department of Health and Human Services. Physical Activity Guidelines for Americans, 2nd ed. Washington, D.C.: Author; 2018.

3. U.S. Department of Health and Human Services, Office of Disease Prevention and Health Promotion. Healthy People 2020. https:// www.healthypeople.gov/2020. Accessed April 3, 2020.

4. U.S. Department of Health and Human Services, Office of Disease Prevention and Health Promotion. Increase the proportion of adolescents who do enough aerobic physical activity-PA-06. https:// health.gov/healthypeople/objectives-and-data/browse-objectives/ physical-activity/increase-proportion-adolescents-who-do-enoughaerobic-physical-activity-pa-06. Accessed August 31, 2020.

5. U.S. Department of Health and Human Services, Office of Disease Prevention and Health Promotion. Increase the proportion of children who do enough aerobic physical activity-PA-09. https://health.gov/ healthypeople/objectives-and-data/browse-objectives/physical-activity/ increase-proportion-children-who-do-enough-aerobic-physical-activitypa-09. Accessed August 31, 2020.

6. Kann L, McManus T, Harris WA, et al. Youth risk behavior surveillance-United States, 2017. MMWR Surveill Summ. 2018;67(8): 1-114. PubMed ID: 29902162 doi:10.15585/mmwr.ss6708a1

7. National Center for HIV/AIDS, Viral Hepatitis, STD, and TB Prevention, Division of Adolescent and School Health. 2015 YRBS Data
User's Guide. 2016. https://www.cdc.gov/healthyyouth/data/yrbs/ pdf/2015/2015_yrbs-data-users-guide.pdf. Accessed April 3, 2020.

8. National Center for HIV/AIDS, Viral Hepatitis, STD, and TB Prevention, Division of Adolescent and School Health. 2017 YRBS Data User's Guide. 2018. https://www.cdc.gov/healthyyouth/data/yrbs/pdf/ 2017/2017_YRBS_Data_Users_Guide.pdf. Accessed April 3, 2020.

9. Ghandour RM, Jones JR, Lebrun-Harris LA, et al. The design and implementation of the 2016 National Survey of Children's Health. Matern Child Health J. 2018;22(8):1093-1102. PubMed ID: 29744710 doi:10.1007/s10995-018-2526-x

10. Carlson SA, Densmore D, Fulton JE, Yore MM, Kohl HW, III. Differences in physical activity prevalence and trends from 3 US surveillance systems: NHIS, NHANES, and BRFSS. $J$ Phys Act Health. 2009;6(s1):S18-S27. doi:10.1123/jpah.6.s1.s18

11. Li C, Balluz LS, Ford ES, Okoro CA, Zhao G, Pierannunzi C. A comparison of prevalence estimates for selected health indicators and chronic diseases or conditions from the Behavioral Risk Factor Surveillance System, the National Health Interview Survey, and the National Health and Nutrition Examination Survey, 2007-2008. Prev Med. 2012;54(6):381-387. PubMed ID: 22521996 doi:10. 1016/j.ypmed.2012.04.003

12. Whitfield GP, Paul P, Wendel AM. Active transportation surveillance-United States, 1999-2012. MMWR Surveill Summ. 2015; 64(7):1-17. doi:10.15585/mmwr.ss6407a1

13. Anderson SE, Economos CD, Must A. Active play and screen time in US children aged 4 to 11 years in relation to sociodemographic and weight status characteristics: a nationally representative crosssectional analysis. BMC Public Health. 2008;8(366). doi:10.1186/ 1471-2458-8-366

14. Belcher BR, Berrigan D, Dodd KW, Emken BA, Chou CP, Spruijt-Metz D. Physical activity in US youth: effect of race/ethnicity, age, gender, and weight status. Med Sci Sports Exerc. 2010;42(12): 2211-2221. PubMed ID: 21084930 doi:10.1249/MSS.0b013e3181 elfba9

15. Gordon-Larsen P, McMurray RG, Popkin BM. Adolescent physical activity and inactivity vary by ethnicity: The National Longitudinal Study of Adolescent Health. J Pediatr. 1999;135(3):301-306. PubMed ID: 10484793 doi:10.1016/S0022-3476(99)70124-1

16. U.S. Department of Health and Human Services, Health Resources and Services Administration, Maternal and Child Health Bureau. National Performance Measures. https://mchb.tvisdata.hrsa.gov/ PrioritiesAndMeasures/NationalPerformanceMeasures. Accessed May 29, 2020.

17. U.S. Department of Commerce, Economics and Statistics Administration, U.S. Census Bureau. 2016 National Survey of Children's Health Methodology Report. 2018. https://www.census.gov/content/ dam/Census/programs-surveys/nsch/tech-documentation/methodology/ 2016-NSCH-Methodology-Report.pdf. Accessed April 3, 2020.

18. U.S. Department of Commerce, Economics and Statistics Administration, U.S. Census Bureau. 2017 National Survey of Children's Health Methodology Report. 2018. https://www.census.gov/content/ dam/Census/programs-surveys/nsch/tech-documentation/methodology/ 2017-NSCH-Methodology-Report.pdf. Accessed April 3, 2020.

19. Kann L, McManus T, Harris WA, et al. Youth risk behavior surveillance-United States, 2015. MMWR Surveill Summ. 2016;65(6): 1-174. PubMed ID: 27280474 doi:10.15585/mmwr.ss6506a1

20. Sallis JF, Buono MJ, Roby JJ, Micale FG, Nelson JA. Seven-day recall and other physical activity self-reports in children and adolescents. Med Sci Sports Exerc. 1993;25(1):99-108. PubMed ID: 8423762 doi:10.1249/00005768-199301000-00014

21. Chinapaw MJ, Mokkink LB, van Poppel MN, van Mechelen W, Terwee CB. Physical activity questionnaires for youth: a systematic 
review of measurement properties. Sports Med. 2010;40(7):539-563. PubMed ID: 20545380 doi:10.2165/11530770-000000000-00000

22. Sallis JF. Self-report measures of children's physical activity. $J$ Sch Health. 1991;61(5):215-219. PubMed ID: 1943046 doi:10.1111/j. 1746-1561.1991.tb06017.x

23. Olson KM. Do 'knowledgeable' respondents really know more? A comparison of parent and teen reports of teen spending. Paper presented at: 58th Annual Meeting of the American Association for Public Opinion Research; August 16, 2003; Nashville, TN.

24. Glover M, Hadwen G, Chelimo C, et al. Parent versus child reporting of tobacco smoke exposure at home and in the car. N Z Med J. 2013; 126(1375):37-47. PubMed ID: 23824023

25. Burrows TL, Truby H, Morgan PJ, Callister R, Davies PSW, Collins CE. A comparison and validation of child versus parent reporting of children's energy intake using food frequency questionnaires versus food records: who's an accurate reporter? Clin Nutr. 2012;32(4): 613-618. PubMed ID: 23206381 doi:10.1016/j.clnu.2012.11.006

26. Knox M, King C, Hanna GL, Logan D, Ghaziuddin N. Aggressive behavior in clinically depressed adolescents. J Am Acad Child Adolesc Psychiatry. 2000;39(5):611-618. PubMed ID: 10802979 doi:10.1097/00004583-200005000-00015

27. U.S. Department of Commerce, Economics and Statistics Administration, U.S. Census Bureau. 2016 National Survey of Children's Health Nonresponse Bias Analysis. 2018. https://census.gov/content/ dam/Census/programs-surveys/nsch/tech-documentation/nonresponsebias-analysis/NSCH_2016_Nonresponse_Bias_Analysis_Update.pdf. Accessed April 3, 2020.

28. U.S. Department of Commerce, Economics and Statistics Administration, U.S. Census Bureau. 2017 National Survey of Children's Health Nonresponse Bias Analysis. 2019. https://census.gov/content/ dam/Census/programs-surveys/nsch/tech-documentation/nonresponsebias-analysis/NSCH_2017_Nonresponse_Bias_Analysis.pdf. Accessed April 3, 2020.

29. Dowda M, Pate RR, Sallis JF, et al. Agreement between studentreported and proxy-reported physical activity questionnaires. Pediatr Exerc Sci. 2007;19(3):310-318. PubMed ID: 18019589 doi:10.1123/ pes.19.3.310

30. Miller J, Pereira M, Wolfson J, Laska M, Nelson T, NeumarkSztainer D. Developmental trends and determinants of physical activity from adolescence to adulthood differ by ethnicity/race and sex. J Phys Act Health. 2018;15(5):345-354. PubMed ID: 29421966 doi:10.1123/jpah.2017-0287

31. Troiano RP, Berrigan D, Dodd KW, Masse LC, Tilert T, McDowell M. Physical activity in the United States measured by accelerometer. Med Sci Sports Exerc. 2007;40(1):181-188. doi:10.1249/mss. 0b013e31815a51b3

32. Whitt-Glover MC, Taylor WC, Floyd MF, Yore MM, Yancey AK, Matthews CE. Disparities in physical activity and sedentary behaviors among US children and adolescents: prevalence, correlates, and intervention implications. J Public Health Policy. 2009;30(S1): S309-S334. doi:10.1057/jphp.2008.46

33. Sallis JF, Prochaska JJ, Taylor WC. A review of correlates of physical activity of children and adolescents. Med Sci Sports Exerc. 2000; 32(5):963-975. PubMed ID: 10795788 doi:10.1097/00005768200005000-00014

34. Committee on Physical Activity and Physical Education in the School Environment, Food and Nutrition Board, Institute of Medicine. Educating the Student Body: Taking Physical Activity and Physical Education to Schools. Washington, D.C.: National Academies Press; 2013.
35. Butcher K, Sallis JF, Mayer JA, Woodruff S. Correlates of physical activity guideline compliance for adolescents in 100 U.S. cities. J Adolesc Health. 2008;42(4):360-368. PubMed ID: 18346661 doi: 10.1016/j.jadohealth.2007.09.025

36. Finkelstein DM, Petersen DM, Schottenfeld LS. Promoting children's physical activity in low-income communities in Colorado: what are the barriers and opportunities? Prev Chronic Dis. 2017;14(E134): 1-10. doi:10.5888/pcd14.170111

37. Harris CD, Paul P, Young R, Zhang X, Fulton JE. Park access among school-age youth in the United States. J Phys Act Health. 2015; 12(s1):S94-S101. doi:10.1123/jpah.2015-0119

38. Sterdt E, Liersch S, Walter U. Correlates of physical activity of children and adolescents: a systematic review of reviews. Health Educ J. 2014;73(1):72-89. doi:10.1177/0017896912469578

39. O'Donoghue G, Kennedy A, Puggina A, et al. Socio-economic determinants of physical activity across the life course: a "DEterminants of DIet and Physical ACtivity" (DEDIPAC) umbrella literature review. PLoS One. 2018;13(1):e0190737. PubMed ID: 29351286 doi:10.1371/journal.pone.0190737

40. Stalsberg R, Pedersen AV. Effects of socioeconomic status on the physical activity in adolescents: a systematic review of the evidence. Scand J Med Sci Sports. 2010;20(3):368-383. PubMed ID: 20136763 doi:10.1111/j.1600-0838.2009.01047.x

41. Zhao J, Settles BH. Environmental correlates of children's physical activity and obesity. Am J Health Behav. 2014;38(1):124-133. PubMed ID: 24034687 doi:10.5993/AJHB.38.1.13

42. Wende ME, Stowe EW, Eberth JM, et al. Spatial clustering patterns and regional variations for food and physical activity environments across the United States. Int J Environ Health Res. 2020:1-15. doi:10. 1080/09603123.2020.1713304

43. Bradley RH, McRitchie S, Houts RM, Nader P, O’Brien M. Parenting and the decline of physical activity from age 9 to 15 . Int J Behav Nutr Phys Act. 2011;8(33):1-10. doi:10.1186/14795868-8-33

44. National Center for Chronic Disease Prevention and Health Promotion, Division of Nutrition, Physical Activity, and Obesity. Nutrition, physical activity, and obesity: data, trends and maps. Centers for Disease Control and Prevention. Updated November 6, 2019. https:// www.cdc.gov/nccdphp/dnpao/data-trends-maps/index.html. Accessed April 3, 2020.

45. The Child \& Adolescent Health Measurement Initiative. NSCH Interactive Data Query (2016-Present). https://www.childhealth data.org/browse/survey. Accessed April 3, 2020.

46. Centers for Disease Control and Prevention. 1991-2019 High School Youth Risk Behavior Survey data. http://nccd.cdc.gov/youthonline/. Accessed April 3, 2020.

47. Corder K, Ekelund U, Steele RM, Wareham NJ, Brage S. Assessment of physical activity in youth. $J$ Appl Physiol. 2008;105(3):977-987. PubMed ID: 18635884 doi:10.1152/japplphysiol.00094.2008

48. Sallis JF, Saelens BE. Assessment of physical activity by self-report: status, limitations, and future directions. Res Q Exerc Sport. 2000; 71(sup2):1-14. doi:10.1080/02701367.2000.11082780

49. Sirard JR, Pate RR. Physical activity assessment in children and adolescents. Sports Med. 2001;31(6):439-454. PubMed ID: 11394563 doi:10.2165/00007256-200131060-00004

50. Williamson C, Kelly P, Strain T. Different analysis methods of Scottish and English child physical activity data explain the majority of the difference between the national prevalence estimates. BMC Public Health. 2019;19(171):1-9. doi:10.1186/s12889-019$6517-7$ 